\title{
Experimental characterization of pantograph arcs and transient conducted phenomena in DC railways
}

\author{
Andrea Mariscotti ${ }^{1}$, Domenico Giordano ${ }^{2}$ \\ ${ }^{1}$ ASTM Sagl, Via Comacini 7, 6830 Chiasso, Switzerland \\ 2 Istituto Nazionale di Ricerca Metrologica (INRIM), Strada delle Cacce 91, 10135 Torino, Italy
}

\begin{abstract}
An electric arc is an example of a transient event that is quite common in electrified transportation systems as by-product of the current collection mechanism. As a broadband transient, an electric arc excites a wide range of (often oscillatory) responses related to the substation and onboard filters, as well as the line resonances and anti-resonances. Similarly do the charging of onboard filter and other related inrush events. This work considers the electrical characteristics of these transients and of the excited responses in order to define their typical spectral signatures in DC railways and take them into account concerning their impact on Power Quality measurements and the measurements of instruments deployed onboard.
\end{abstract}

Section: RESEARCH PAPER

Keywords: Arc discharge; electric arc; power quality; rail transportation.

Citation: Andrea Mariscotti, Domenico Giordano, Experimental characterization of pantograph arcs and transient conducted phenomena in DC railways, Acta IMEKO, vol. 9, no. 2, article 3, June 2020, identifier: IMEKO-ACTA-09 (2020)-02-03

Editor: Alexandru Salceanu, Technical University of Iasi, Romania

Received December 19, 2019; In final form March 13, 2020; Published June 2020

Copyright: This is an open-access article distributed under the terms of the Creative Commons Attribution 3.0 License, which permits unrestricted use, distribution, and reproduction in any medium, provided the original author and source are credited.

Funding: This work was developed within the 16ENG04 MyRailS Project and supported by the EMPIR programme (European Union's Horizon 2020 Research and Innovation Programme) and by the Swiss State Secretariat for Education, Research and Innovation (SERI) under contract number 17.00127.

Corresponding author: Andrea Mariscotti, e-mail: andrea.mariscotti@astm-e.ch

\section{INTRODUCTION}

Power is transferred from supply substations to the rolling stock (locomotive or electro-train) through a sliding contact between the supply line (either a catenary or a third rail) and the current collection system (correspondingly, a pantograph or a shoegear). Overhead conductors (the so-called catenary or Overhead Contact Line [OCL]) are used in many railway systems, including tramways, metro applications, and some light railways, in which a third rail distribution is preferred. There are cases in which the distribution in tunnels occurs through a rigid catenary, which is an overhead busbar. Both the pantograph and the sliding shoe are controlled to ensure good mechanical contact, exerting an adequate force and thus contact pressure. Mechanical oscillations and bounces, including tilting in curves and irregularity of the track, cause detachments that in turn can cause arcing; other reasons for electric arcing include defects or oxidation on the surfaces of the catenary or of the sliding contact and the presence of ice. The large current transferred through the sliding contact makes the current collection and the control of arcing some of the most critical elements of electrified railways: the contact cross-section may account for up to a tenth of square millimetres, whereas the current intensity of a single collection point may reach values of several thousand amps. Predictive maintenance and monitoring can help the prevention of the degradation of the sliding contact and reduce the failure rate of the elements involved [1][2]. Failures are often caused by excessive heating and erosion, of which electric arcing is a contributory cause. Arcing is also a consequence of excessive heating: the higher the arcing, the higher the heating and the wearing of surfaces, with increased oxidation and erosion, from which there is a local increase in the arcing rate.

The number of electric arcs is indicated as a direct index for the assessment of the quality of current collection in EN 50367 [3], sec. 7.3 'Percentage of arcing'; thus, their identification is a relevant problem: arcs can be detected by measuring the light emissions (mostly blue and ultraviolet) [4]-[6], the electromagnetic emissions [7][8], or by processing the pantograph electrical quantities [9]-[11], looking for typical distortions, such as voltage jumps and oscillations. The presence of many similar transients can confuse detection algorithms, which can be beneficial in an analysis of the related phenomena and system response, as carried out in this work. 
An electric arc, as anticipated, is a source of electromagnetic emissions and disturbance [7][8], both conducted and radiated, impacting the power quality of the line [12] as well as the measurement of electrical quantities [12]-[15] and radio systems for signalling and communications [16]-[19]. An electric arc, as with any other steep transient, is not a standalone event; rather, it is a broadband excitation for the entire electric traction system and triggers other conducted phenomena, such as resonances, oscillations, and overvoltages.

The majority of the works in the relevant literature have covered AC applications, driven by the interest in and the rapid development of high-speed lines as well as by critical scenarios of winter frozen lines and long-distance lines, which require expensive maintenance and surveillance [20]-[22].

However, DC railways (the term 'railways' includes all the rapid transit, light railways, tramways, etc. with a DC supply) feature more intense arcing due to two factors: Power is supplied through a DC voltage of a significant amplitude (between $600 \mathrm{~V}$ and $3000 \mathrm{Vdc}$, with maximum permanent voltages up to about $4000 \mathrm{~V}$ ), and the current intensity can be an order of magnitude larger than AC railways.

Within the EMPIR 16ENG04 MyRailS research project [23], which aims to develop the metrological framework to foster and demonstrate the energy efficiency of railway systems [24], the focus has been on DC electric arcs and their influence on the behaviour of the system, measurements, and measurement accuracy. To this end, an essential activity is the definition of a reliable and comprehensive electrical model of the system, in which the arc events originate and propagate. This system includes all the elements of a DC railway [25]-[28]:

- Electrical Substations (ESSs) equipped with diode rectifier groups, representing a non-linear element;

- the catenary and the return circuit, extensively modelled by means of lumped and distributed parameter models for the propagation of conducted emissions; and

- the locomotive or electro-train, subdivided between the pantograph interface and the onboard circuits, including the onboard filters and the power converters.

The objective is the characterization of the interaction of the electric arc at the pantograph-catenary interface of a DC vehicle with the rest of the network. The desired result is a better understanding of the circuit dynamic response, of the variability caused by varying parameters or parameters that are not known to be accurate, and of the assessment of the impact on connected circuits, particularly measurement systems such as those uses for energy consumption [24]. This work goes beyond the evaluation in [12] of electric arcs impacting pantograph voltage waveform and its Power Quality (PQ) features. The approach of this work is practical, using circuit modelling for a better understanding of measured waveforms, with the aim of classifying the typical transients, including the identification of worst-case scenarios, as shown in the IMEKO TC4 Symposium preliminary work [29].

\section{ELECTRIC ARC AND FILTER TRANSIENTS}

As explained in the Introduction, although the focus of this paper is the electric arc as a source of radiated and conducted disturbance and as a cause of the wearing of the sliding contact elements, there are other transients in DC railways that have a similar excitation in the network response and can be assimilated to electric arcs from a phenomenological viewpoint.

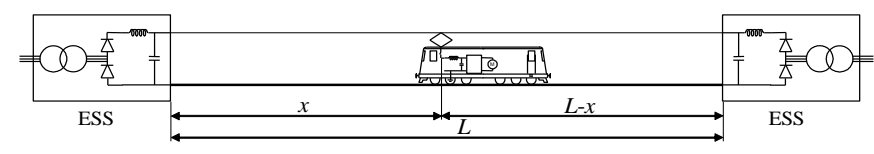

Figure 1. A simplified network equivalent circuit (traction line, substation and vehicle) for supporting the interpretation of the observed phenomena.

The general equivalent circuit of a DC vehicle fed by a DC line is shown in Figure 1, where the elements contributing to the overall transient response are highlighted, particularly those that determine the oscillatory response, as described in the following section.

\subsection{Electric arc}

A typical V-I characteristic of a DC arc can be summarized as follows: At a low current (tens of amperes), a constant arc power law can be assigned; for larger currents above a specific threshold, the voltage level reaches a plateau and no longer depends on the current value. An interesting discussion of more complete dynamic models (starting from Mayr's model) can be found e.g. in [30]. Various V-I arc characteristic curves for lowvoltage DC arcs with static electrodes were provided by Paukert [31]: He collected data provided by seven research institutes with currents ranging from $100 \mathrm{~A}$ to $100 \mathrm{kA}$.

The electric arc can thus be represented with a combination of equivalent circuits: a resistor variable with the intensity of the flowing current (getting smaller along with the increasing current) and a voltage source that stabilizes to the plateau for a current exceeding a threshold value. As detailed in Section 3.4, the arc resistance is extremely small and does not contribute significantly to circuit damping. The arc conduction voltage instead appears suddenly at arc ignition and represents the main electric phenomena related to the arc event.

\subsection{Pantograph operation and onboard filter charge}

Whenever the pantograph is operated by raising or lowering it, a transient occurs: The former is more interesting than the latter, because the onboard measuring system can thoroughly measure the development of the transient responses through the established electrical connection at the sliding contact. Pantograph raising is carried out with the onboard circuit breaker (High-Speed Circuit Breaker [HSCB]) open in order to avoid the sudden intense charging current of the onboard filter; rather, a charging resistor $R_{c b}$ is used to control it, as shown in Figure 2.

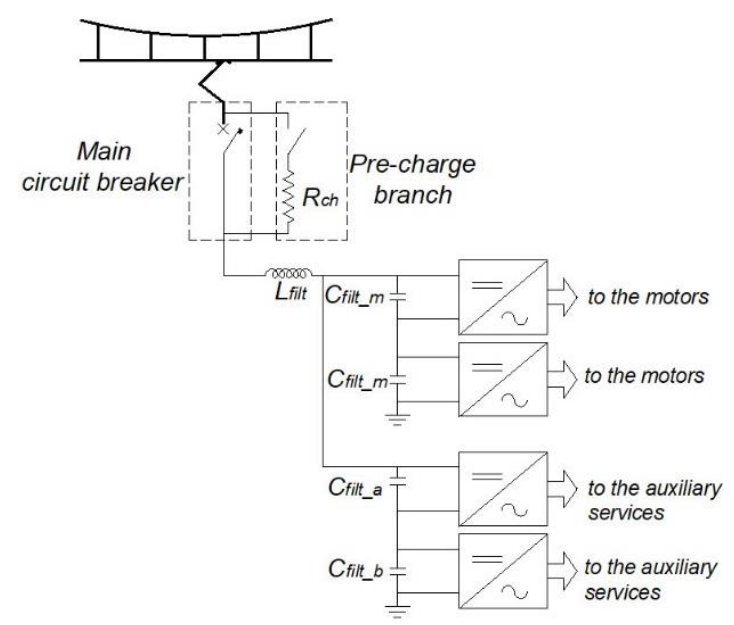

Figure 2. Electrical scheme of the E464 locomotive, showing the onboard LC filter, the main circuit breaker, and the pre-charging circuit with the limiting resistor $R_{c h}$ [32]. 
During the pre-charge, the capacitors are charged with the pantograph current flowing through the limiting resistor $R_{c b}$ and the filter inductor $L_{\text {filt }}$ of $8.5 \mathrm{mH}$. After $0.8 \mathrm{~s}$, the voltage across the capacitor bank (made of all parallel-connected capacitors) reaches a threshold that is sufficient to accelerate charging through the main HSCB, closing it in order to bypass the charging resistor. A smaller current impulse is thus absorbed by the capacitor bank, where the limiting elements remain the filter inductor $L_{f i l t}$ and the line impedance $Z_{p}$. The equivalent $R L C$ series circuit, which during pre-charge was over-damped thanks to the $\mathrm{R}_{c b}$ resistor, becomes thus under-damped, with visible oscillations.

\section{CATENARY - VEHICLE ELECTRIC INTERACTION}

A simplified equivalent circuit has been introduced in Section 0 in order to discuss and interpret the observed phenomena related to the transient response of the network. Network dynamics require that sophisticated models are used, including, at least, the main characterizing elements: the non-linearity of the substation diodes, the extended frequency response of the traction line accounting for the first two or three resonance modes, and a correct estimate and inclusion of damping factors at resonances. Studies on the characterization of DC arcs have always used simpler lumped-parameter models with a single pi cell for the line and with the inductance and capacitance values fixed to a predetermined line length [33]-[35]. It is known that lumped-parameter models are less accurate than distributedparameter models, particularly with circuit resonances, and that they are subject to a maximum frequency constraint: the higher the desired upper frequency limit, the higher the number of required cells [36]. Having observed repeated resonance oscillations triggered by transient events, a circuit model is used for the analysis of system response; the model was introduced in the IMEKO TC4 Symposium paper [29], where some more details on expressions can be found.

A traction line, electrically continuous and fed at ESSs, has a frequency behaviour characterized by a series of resonances and anti-resonances, starting at a low frequency with a resistiveinductive behaviour. The frequency response of the traction line is influenced by the said ESSs with LC resonant filters, representing a shunting point thanks to the low impedance [37]: Starting from around several hundred $\mathrm{Hz}$ (some octaves above the resonance frequency of the substation LC filter, which in Italy is located slightly above $100 \mathrm{~Hz}$ ), the portion of the line between two ESSs is electrically decoupled from the adjacent sections. Concerning our problem, the line section is seen as tapped by the pantograph, with left and right parts in electric parallel: The equivalent impedance made of the two left and right sections in electric parallel is known as the 'pantograph impedance' $Z_{p}$. Due to the different lengths of the two sections, the frequency responses of the two sections mix, resulting in an overall response that has resonance frequencies approximately fixed and independent of the train position, whereas antiresonances move with the train. At resonances, what changes with the train position is the damping factor, which is at its maximum when the train is in the middle - farthest from the two ESSs. Approaching one of the ESSs, the peak flattens and broadens. The train position is thus quite important in the interpretation of the experimental results and the verification of the agreement with the simulation. The theoretical expression of $Z_{p}$ is:
$Z_{p}=Z_{c} \frac{\tanh (\gamma \times L) \tanh [\gamma(1-x) L]}{\tanh (\gamma x L)+\tanh [\gamma(1-x) L]}$

where $Z_{c}$ is the characteristic impedance of the line, $x$ is the train position, and $L$ is the length of the line section between two ESSs.

For the quantification of $Z_{p}$ and the variability of its main characteristics, the set of parametric curves is as follows. The model is implemented in a compact MATLAB code used for line response study [37][38], based on transmission line equations for the line (a distributed parameter model, including line losses due to e.g. skin effect in the running rails) and lumped circuits described by Kirchhoff equations for the terminal conditions (substations and train). With an assumed return path through the running rails, rail-to-rail capacitance and its significant variability [39] is not a relevant parameter. The program was used for the evaluation of the spread of line responses depending on substation electric parameters and the interaction with the vehicle filter [37][38]. The train is modelled focusing on its input filter, as explained later in Section 3.3. The electric arc is modelled as a generator and a series resistor that simulates the arc resistance.

The geometrical and electric line parameters, including the onboard vehicle filter, considered for the parametric analysis of this Section 3, are shown in Table 1.

\subsection{Influence of the line's geometrical and electrical parameters}

The analysis of the sensitivity of the electrical behaviour and in particular of the pantograph impedance have been carried out a few times in the last 20 years [40]-[42]. In general, changes to the geometry of about $10 \%$ (height of contact wire, height of running rails from the reference plane, and horizontal displacement) influence the location of the resonance and antiresonance marginally (about $1-1.5 \%$ sensitivity, so one-tenth) and more remarkably affect the impedance value at resonance (10\%, so a $1: 1$ proportion). Similarly, the variability of the electrical parameters (such as soil resistivity and the magnetic permeability of rails) mainly affects the impedance at resonance ( $20 \%$ of a variation against more than a tenfold variation of the said electrical parameters), whereas the resonance and anti-

Table 1. Electrical and geometrical parameters of the traction line and onboard filter.

\begin{tabular}{|c|c|}
\hline Parameters & Values \\
\hline $\begin{array}{l}\text { Contact wire (copper): height }(\mathrm{m}) \text {, cross } \\
\text { section }\left(\mathrm{mm}^{2}\right) \text {, resistivity }(\mu \Omega / \mathrm{m})\end{array}$ & $5.2,240,0.018$ \\
\hline $\begin{array}{l}\text { Suspension wire (bronze): height }(\mathrm{m}) \text {, cross } \\
\text { section }\left(\mathrm{mm}^{2}\right) \text {, resistivity }(\mu \Omega / \mathrm{m})\end{array}$ & $5.6,200,0.05$ \\
\hline $\begin{array}{l}\text { Running rail: gauge }(\mathrm{m}) \text {, height above ref }(\mathrm{m}) \text {, } \\
\text { cross section }\left(\mathrm{mm}^{2}\right) \text {, relative permeability, } \\
\text { resistivity }(\mu \Omega / \mathrm{m})\end{array}$ & $1.5,0.1,7600,50,0.22$ \\
\hline Rectifier: rated power (MW) & 5.4 \\
\hline $\begin{array}{l}\text { Transformer: rated power (MVA), rated sec. } \\
\text { voltage (kV), short-circuit voltage (\%) }\end{array}$ & $5.75,2.71,10 \%$ \\
\hline Substation filter: induct. $(\mathrm{mH})$, capac. $(\mu \mathrm{F})$ & 6,360 \\
\hline \multicolumn{2}{|l|}{ Rolling stock filter: induct. $(\mathrm{mH})$, capac. (mF) } \\
\hline E402B & $16,3.2$ \\
\hline $\mathrm{E} 412$ & $21,9.47$ \\
\hline TAF & $18,2.5$ \\
\hline ETR460 & 21,4 \\
\hline
\end{tabular}


resonance frequencies are almost unaffected, changing less than $1 \%$. The variability of the rail internal inductance, amounting to the geometrical external inductance term, is probably the most relevant influencing factor and was implicitly taken into account in [40] by varying the magnetic permeability of the rail steel.

\subsection{Influence of the train position}

The train position influences not only the anti-resonance frequency but also the height of the resonance peak i.e. the factor of merit or damping (not the resonance frequency, which depends instead on the length of the line section). Accurate expressions can be found in [37]. The factor of merit at resonance may be large, especially when the train is far away from
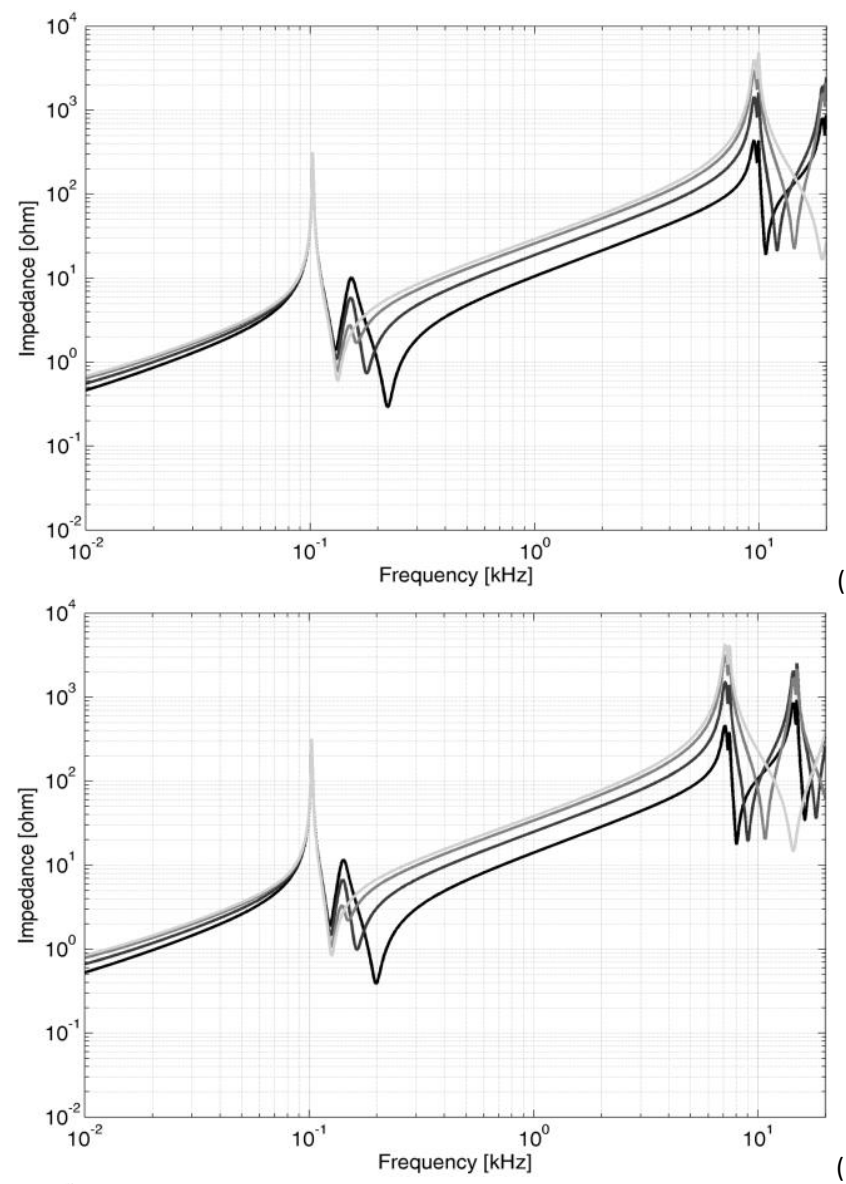

(b)

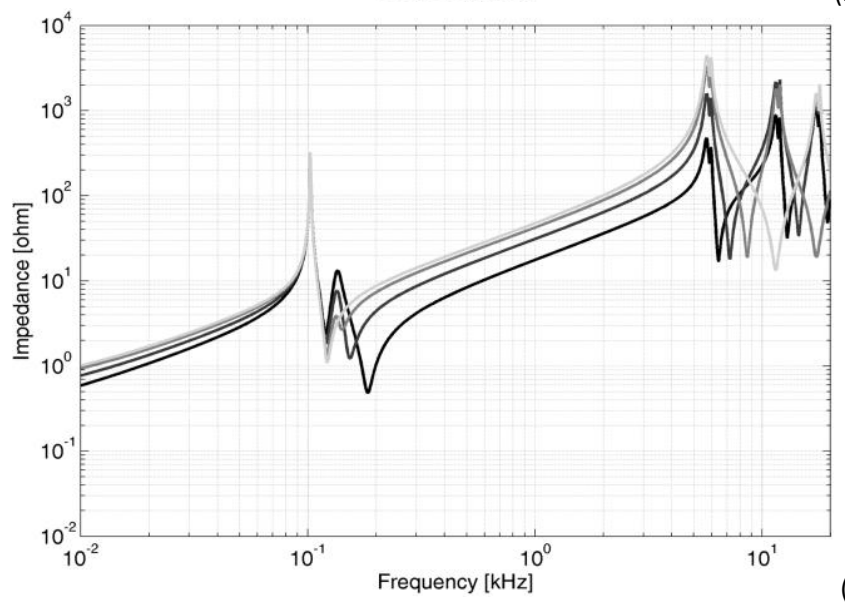

(c)

Figure 3. $Z_{p}$ for 3 ESSs separations $L$ : (a) $15 \mathrm{~km}$, (b) $20 \mathrm{~km}$, (c) $25 \mathrm{~km}$; no loco filter; 4 train positions (black to light grey) $x=0.1,0.2,0.33,0.5 L$ [29]. the substations, with a significant effect in terms of voltage amplification when excited by the pantograph transient.

Three sets of curves are shown in Figure 3 for three different ESS separation distances $L$, with curves for four train positions $x$, measured relative to $L: x=0.1,0.2,0.33,0.5 \mathrm{~L}$. Positions beyond the mid-point in the $0.5-1.0 \mathrm{~L}$ interval give identical results.

The pair of resonance/anti-resonance at a low frequency is due to the ESS filter and may be slightly variable, depending on the values of inductance and capacitance implemented at the ESS. As a consequence, a significant $100 \mathrm{~Hz}$ component is visible, generated by the ESS rectifier and amplified by the filter resonance.

At a high frequency, the anti-resonance frequency is variable and evenly distributed approximately between $6.5 \mathrm{kHz}$ and $20 \mathrm{kHz}$, depending on length $L$ and train position $x$. As for the voltage components susceptible to the line resonances, there should be current components enhanced by anti-resonances: The pantograph current will show a persistent response at these frequencies, continuously excited by various types of transients and high-frequency components, including the steep front of the electric arc event.

The increasing line resistance is remarked: At $120-200 \mathrm{~Hz}$, anti-resonances caused by the interaction of the substation and vehicle filter, the values are 0.5-2 $\Omega$, whereas at the first highfrequency anti-resonance, the minima are about $20 \Omega$, so they are larger by an order of magnitude due to increased losses and skin effect.

\subsection{Onboard equivalent circuit and input filter effect}

The onboard input filter is a low-pass LC filter with a typical resonance between $15 \mathrm{~Hz}$ and $25 \mathrm{~Hz}$. Regardless of the loading of traction and auxiliaries (seen as an equivalent resistor parallel to the capacitor bank), the shunting effect across the capacitor is negligible for frequencies above some tens of $\mathrm{Hz}$; for this reason, only the LC on-board filter is considered. The onboard filter is parallel to $Z_{p}$ when seen from the pantograph port. Ideally, its loading effect is negligible for frequencies above a hundred $\mathrm{Hz}$, since the filter inductance is larger than the overall equivalent line inductance seen at the pantograph for lengths up to about $25-30 \mathrm{~km}$. As shown in Figure 4, the curves are quite variable up to $100 \mathrm{~Hz}$; from here onward, only a negligible shift between curves can be seen.

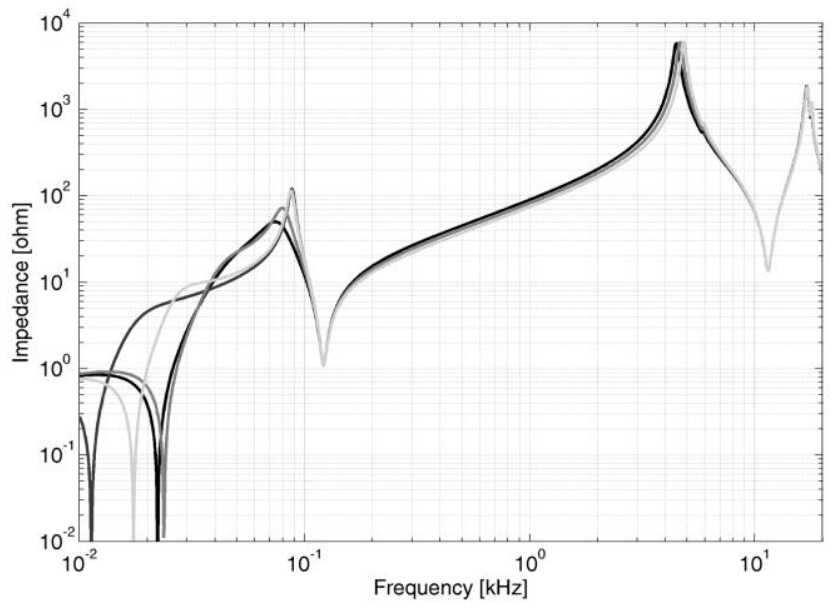

Figure 4. Sensitivity analysis of $Z_{p}$ for the varying vehicle input filter: E402B, E412, TAF, ETR460 (see Table 1) [29]. 


\subsection{Influence of the electric arc resistance}

The electric arc is a dynamic phenomenon with a resistance that varies during the occurrence of the transient. Arc resistance values have been estimated for DC arcs at various inter-electrode gaps. The arc resistance $R_{a}$ is, in general, negligible, as shown in [2], Figure 14, where values of $10 \mathrm{~m} \Omega$ to $100 \mathrm{~m} \Omega$ are reported. In the case of various types of wearing after long use, the electric contact at the sliding surfaces worsens, and the resistance increases up to ten times [43]. The observed values during preliminary measurements [13] are of the same order (about $0.2 \Omega$ to $0.5 \Omega$ ).

In the equivalent circuit for the pantograph voltage and current at the sliding contact interface, the arc resistance is always in series with $Z_{p}$ (the overall network impedance); voltage and current are measured immediately after it, either on the roof or inside the rolling stock. It is observed that arc resistance values larger than observed will not cause any appreciable change of the overall series impedance and of current flow, being small compared to the overall line resistance and reactance (see $Z_{p}$ values in Figure 3).

\subsection{Overview of the electric phenomena justified by the model}

Based on the examined characteristics of the frequency response of the traction line feeding the vehicle through the pantograph, the following considerations are anticipated regarding the conducted phenomena following a transient.

1) The low-frequency resonance related to the substation filter is responsible not only for the low-frequency voltage oscillation but also for the persistent $100 \mathrm{~Hz}$ ripple, where the excitation signal comes from the rectification of the negative sequence component of the $50 \mathrm{~Hz}$ fundamental of the high-voltage side.

2) Another low-frequency oscillatory response is observed due to the transient response of the onboard filter; considering the filter parameter values and based on experience, the resonance frequency is located between about $15 \mathrm{~Hz}$ and $25 \mathrm{~Hz}$ for a broad range of vehicles. The large inductance value accounts for several $\mathrm{km}$ of traction line and can thus drive its oscillatory current into the system.

3) The onboard filter oscillation has slightly non-linear behavior in that its positive and negative half-cycles are unequal, with the positive ones slightly longer. The reason is the non-

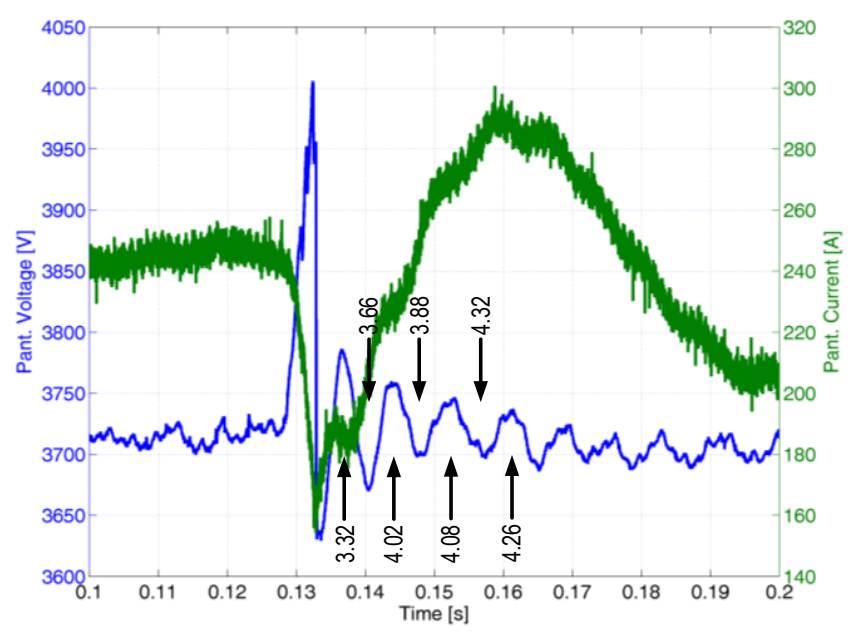

Figure 5. Electric arc event during braking (positive voltage jump). The numbers refer to the estimated half-cycle duration in ms during the oscillatory transient, passing from the transient response of the ESS filter back to the underlying $100 \mathrm{~Hz}$ ripple. linearity of the diodes in the substation rectifiers, allowing for the conduction of the current pulled from the line but necessitating the bias of other trains loading the same line to let a 'negative' current flow in the opposite direction. Unless the bias current is large (a nearby train pulling traction current), bringing the diodes to a full conduction state, the non-linearity is visible and can cause significant distortion.

4) The initial steep leading edge (at the contact detachment for an electric arc or at the insertion of the charging resistor) has a fairly broad range of components able to excite the highfrequency resonances of the line; the first resonance is located between $5 \mathrm{kHz}$ and $10 \mathrm{kHz}$ depending on the separation of substations (up to $30 \mathrm{~km}$ ), the successive ones roughly at its multiples, with a variable pattern of peaks, depending on train position. The reaction is a burst of faster and slower oscillatory modes with a rapid decay (overall resistance is quite large thanks to several causes of loss), causing rapid voltage changes (positive or negative depending on the direction of the flowing current, leaving or entering the vehicle pantograph, respectively). If it is not an issue for dielectric breakdown, it is a source of significant electromagnetic interference and possibly a cause of increased stress to components.

Reference will be made to this classification when showing and commenting on the experimental results in the next section.

\section{EXPERIMENTAL RESULTS}

The measurements of the pantograph voltage and current were performed along various Italian $3 \mathrm{kV}$ dc lines: a sampling rate of $50 \mathrm{kS} / \mathrm{s}$ and probe bandwidth of about $20 \mathrm{kHz}$. Data were digitized at 16 bits.

\subsection{Electric arc event}

As shown in Figure 5, the arc event triggers voltage oscillations at a frequency slightly larger than $100 \mathrm{~Hz}$ (around $0.14-0.15 \mathrm{~s}$ ), corresponding to the predicted anti-resonance of Figure 3; such faster oscillations (at about $120 \mathrm{~Hz}$ ) are damped and disappear in about five cycles, and the regular $100 \mathrm{~Hz}$ resumes (e.g. beyond $0.19 \mathrm{~s}$ ). The first peak of the current is caused by the excitation of the on-board filter and ESS antiresonances, visible in Figure 3 and Figure 4 at about $10-30 \mathrm{~Hz}$ and $120-150 \mathrm{~Hz}$. The broader oscillation that follows the current peak is due to the transient response of the on-board filter tuned to about $15 \mathrm{~Hz}$, which is not visible in the voltage waveform (besides a slight fluctuation) due to the train position being close to the ESS, the very low line impedance, and, consequently, the voltage drop.

The persistent low-frequency oscillations on the pantograph voltage (caused by the substation ripple mainly at $100 \mathrm{~Hz}$ and $300 \mathrm{~Hz}$ ) hide the high-frequency components that should be located at line resonances that are visible only with a more detailed spectral analysis. To narrow the analysis around the arc event, considering the short duration of the arc, the larger damping at high frequency, and the underlying low-frequency components that cause the local non-stationarity of the extracted time windows, tools with a short duration of the kernel function and yet sufficient frequency resolution are needed: suitable tools may be wavelets and joint time-frequency transforms.

Another example with a much longer distance between the loco and the ESS is shown in Figure 6, where the peak voltage reached by the triggered oscillations is much higher, and the oscillations are more persistent: The $15 \mathrm{~Hz}$ oscillation of the 


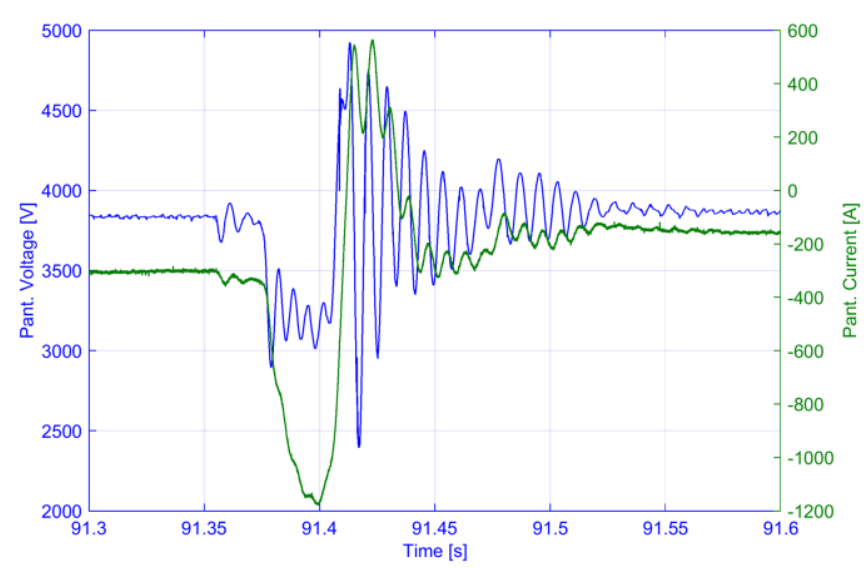

Figure 6. Another electric arc event during traction (negative voltage jump): triggered oscillations with the ESS filter are more intense and persistent and are modulated by the onboard filter transient response, lasting about two cycles (140 ms).

onboard filter is surrounded by repetitive oscillations with the ESS filter of a similar amplitude. Although it is not easy to see, the change of period occurs as well, passing from about $3.2 \mathrm{~ms}$ at the very beginning (about $150 \mathrm{~Hz}$ of resonance frequency) to the steady $5 \mathrm{~ms}$ half-cycle of the $100 \mathrm{~Hz}$ component.

\subsection{Onboard filter charging process}

A similar behaviour is expected for the initial transient when the pantograph line is connected for the charging of the onboard filter. The recorded waveform is shown in Figure 7, focusing on the initial voltage spike (negative, scale divided by 10 in the
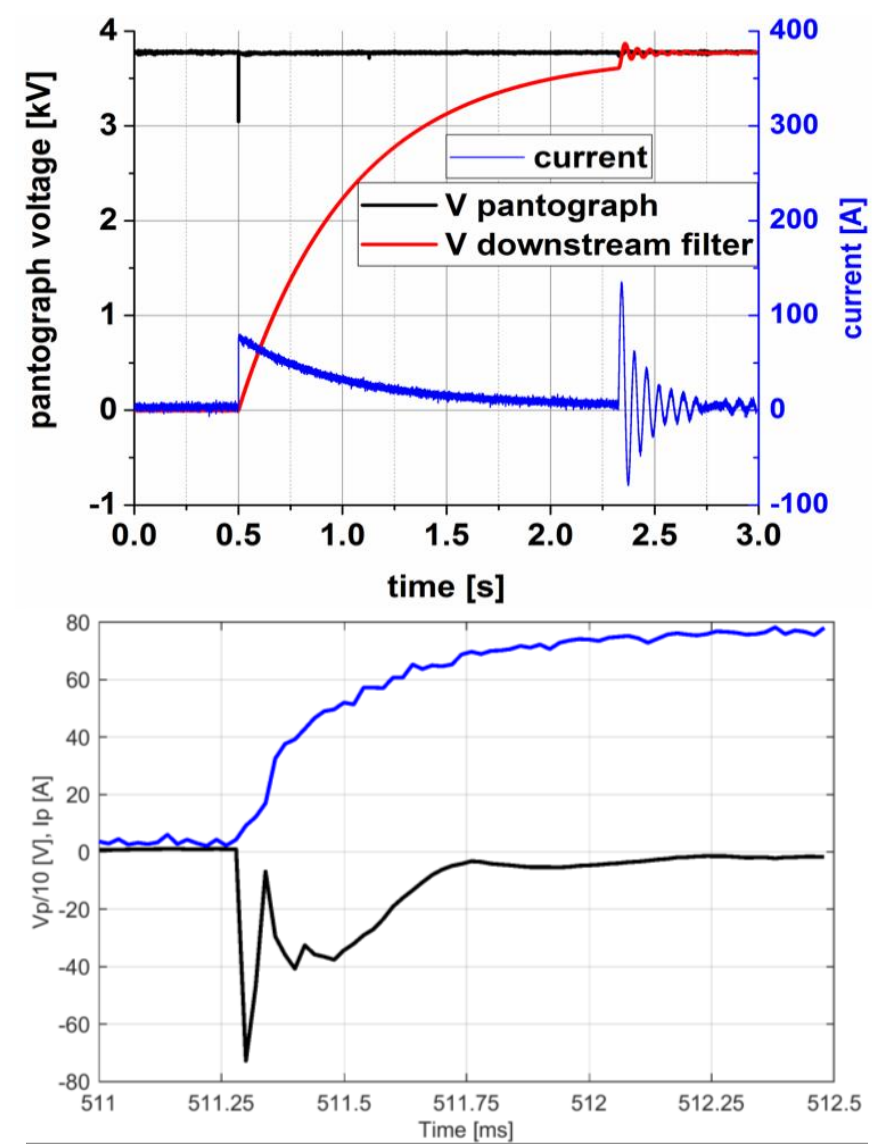

Figure 7. Measured waveforms of pantograph voltage $v_{p}$, pantograph current $i_{p}$ and capacitor voltage downstream of filter $v_{f}$; zoom of the first insertion with resistor $R_{c h}$. figure): The dynamics are very fast, and there are only a few samples along the waveform. The interpretation is that the steplike current absorbed through the charging resistor excites the line resonances, namely the fastest ones at about $20 \mathrm{kHz}$ and above (responsible for the first peak) and then the slower first and second resonance.

\section{DISTURBANCE TO MEASURED ELECTRICAL QUANTITIES}

As discussed in the previous section, the examined transients following the arc or filter pre-charge events may be characterized from three viewpoints:

- They cause significant spikes in the pantograph voltage, both positive and negative, the former being more significant for the stress on components in terms of the maximum temporary voltage; a $5 \mathrm{kV}$ peak was reported in Figure 6; a very fast negative peak is visible in Figure 7.

- Fast peaks indicate a broadband excitation of the line and bring with them fast line oscillations, damped because of line losses at higher frequencies. These oscillations appear as narrowband components but are located generally above the usual harmonics, approximately above $5 \mathrm{kHz}$, as shown in Figure 3.

- Low-frequency oscillations are related to the transient response of the resonant filters, both at substations and onboard. In this case, the damping is much less, and the oscillations may persist for longer time intervals, such as the $100 \mathrm{~ms}$ shown in Figure 6. In general, the transient response of the loco filter is always an issue and may cause frequent out-of-scale readings when carrying out pantograph current measurements for PQ purposes and for demonstrating compliance to limits of emissions based on signalling susceptibility, as explained below.

The voltage spikes may thus represent a significant stress for the components, particularly the sensors connected to the pantograph line, but all these elements must be tested per EN 50124-1, and, in terms of rigorousness, they are exposed to transients related to the line. Reading the standard more accurately, a sensor connected to the pantograph line is 'not powered directly by the contact line', as Table A.1 of EN 501241 says, and this may lead to select a comfortably lower - but more critical - test voltage. The observed overvoltages, although included and covered by the test voltages for dielectric strength, should be considered as a source of dielectric stress.

The observed oscillations have two consequences for the measurement process:

- They add spectral components with a narrowband behaviour, which may be interpreted as emissions from some kind of apparatus, conveying false information in PQ indexes and assessment procedures that are not prepared to exclude such distortions (preliminarily identified in [12]).

- In the case of an expanded scale for better AC reading (after removing the DC component e.g. by measuring using a capacitive divider for the voltage and a Rogowski coil for the current), such transients will cause out-of-scale readings, corrupting the acquired signal for the whole duration of the transient itself. In addition, this underlying signal variability causes issues in spectral leakage by modifying and making the two ends of the time record fed to the Fourier or equivalent analysis quite different. 


\section{CONCLUSIONS}

This paper has presented typical transients of pantograph quantities (voltage $v_{p}$ and current $i_{p}$ ) in DC railways. Such transients (electric arcs and onboard filter charging) have been considered for the excitation of line, substation, and vehicle transient responses, discussing and characterizing the components observable in the measured signals. These components were considered in relation to low- and highfrequency responses, specifically the response of the substation and onboard resonant filters as well as the excitation of the line resonances and anti-resonances, respectively.

The observed phenomena consist of rapid overvoltages/ undervoltages and repeated oscillations, in some cases, with very low damping, thus lasting for $100 \mathrm{~ms}$ and longer. The rapid voltage changes are steep and intense, possibly causing the accelerated aging of connected measuring equipment if they are too frequent, but they are still below the insulation voltage level required for equipment connected to the pantograph line. The observed oscillations correspond to low-frequency components, approximately in the range of 10 to $150 \mathrm{~Hz}$, due to the excited transient response (poles and zeros) of the combined substationnetwork circuit and of the onboard filter. The spectral behaviour is thus the one typical of harmonic emissions that might affect the evaluation of PQ and the calculation of indexes if not properly separated and considered.

This work also addresses indirectly the problem of arc detection, identifying a peculiar spectral behaviour that may be exploited to define a spectral signature of such events, but the onboard filter oscillations alone can be related to other types of transients, such as mechanical and loading transients.

\section{REFERENCES}

[1] G. Wu, J. Wu, W. Wei, Y. Zhou, Z. Yang, G. Gao, Characteristics of the sliding electric contact of pantograph/contact wire systems in electric railways, Energies 11(1) (2018) pp. 17.

[2] G. Bucca, A. Collina, A procedure for the wear prediction of collector strip and contact wire in pantograph-catenary system, Wear 266 (2009) pp. 46-59.

[3] CENELEC EN 50367, Railway applications - Current collection systems - Technical criteria for the interaction between pantograph and overhead line (to achieve free access), 2016.

[4] S. Barmada, M. Raugi, M. Tucci, F. Romano, Arc detection in pantograph-catenary systems by the use of support vector machines-based classification, IET Electrical Systems in Transportation 4(2) (2014) pp. 45-52.

[5] P. Boffi, G. Cattaneo, L. Amoriello, A. Barberis, G. Bucca, M. F. Bocciolone, A. Collina, M. Martinelli, Optical fiber sensors to measure collector performance in the pantograph-catenary interaction, IEEE Trans. on Sensors 9(6) (2009) pp. 635-640.

[6] O. Bruno, A. Landi, M. Papi, L. Sani, Phototube sensor for monitoring the quality of current collection on overhead electric railways, Proc. Instn Mech. Engrs, Part F: J. Rail and Rapid Transit 215 (2001) pp. 231-241.

[7] G. Gao, X. Yan, Z. Yang, W. Wei, Y. Hu, G. Wu, Pantographcatenary arcing detection based on electromagnetic radiation, IEEE Trans. on Electrom. Compat. 61(4) (2019) pp. 983-989.

[8] B. Tellini, M. Macucci, R. Giannetti, G. A. Antonacci, Conducted and radiated interference measurements in the linepantograph system, IEEE Trans. on Instrum. and Meas. 50(6) (2001) pp. 1661-1664.

[9] A. Khoshkbar Sadigh, K. M. Smedley, Fast and precise voltage sag detection method for dynamic voltage restorer (DVR) application, Electric Power Systems Research 130 (2016) pp. 192207.
[10] A. Florio, A. Mariscotti, M. Mazzucchelli, Voltage sag detection based on rectified voltage processing, IEEE Trans. on Power Delivery 19(4) (2004) pp. 1962-1967.

[11] T. Tarasiuk, Simple methods of voltage dip tracking - case study, ACTA IMEKO 6(4) (2017) pp. 80-88.

[12] A. Mariscotti, Characterization of power quality transient phenomena of DC railway traction supply, ACTA IMEKO 1(1) (2012) pp. 26-35.

[13] G. Crotti, D. Giordano, P. Roccato, A. Delle Femine, D. Gallo, C. Landi, M. Luiso, A. Mariscotti, Pantograph-to-OHL arc: conducted effects in DC railway supply system, Proc. of the 9th IEEE Intern. Workshop on Applied Meas. for Power Systems (AMPS), 26-28 September, 2018, Bologna, Italy.

[14] G. Crotti, A. Delle Femine, D. Gallo, D. Giordano, C. Landi, M. Luiso, A. Mariscotti, P. Roccato, Pantograph-to-OHL arc: conducted effects in DC railway supply system, IEEE Trans. on Instrum. and Meas. 68(10) (2019) pp. 3861-3870.

[15] A. Delle Femine, D. Gallo, C. Landi, M. Luiso, Discussion on DC and AC power quality assessment in railway traction supply systems, Proc. of the IEEE Intern. Instrum. and Meas. Tech. Conf. (I2MTC), 20-23 May, 2019, Auckland, New Zealand.

[16] S. Dudoyer, V. Deniau, S. Ambellouis, M. Heddebaut, A. Mariscotti, Classification of transient EM noise depending on their effect on the quality of GSM-R reception, IEEE Trans. on Electrom. Compat. 55(5) (2013) pp. 867-874.

[17] A. Mariscotti, A. Marrese, N. Pasquino, R. Schiano-Lo Moriello, Time and frequency characterization of radiated disturbance in telecommunication bands due to pantograph arcing, Measurement 46 (2013) pp. 4342-4352.

[18] A. Mariscotti, A. Marrese, N. Pasquino, Time and frequency characterization of radiated disturbances in the telecommunications band due to pantograph arcing, Proc. of Intern. Instrum. and Meas. Tech. Conf., 13-16 May, 2012, Graz, Austria.

[19] R. Geise, O. Kerfin, B. Neubauer, G. Zimmer, A. Enders, EMC analysis including receiver characteristics - pantograph arcing and the instrument landing system, IEEE Intern. Symp. on Electrom. Comp., 16-22 August, 2015, Dresden, Germany, pp. 1213-1217.

[20] G. Wu, W. Wei, G. Gao, J. Wu, Y. Zhou, Evolution of the electrical contact of dynamic pantograph-catenary system, Journal of Modern Transportation 24(2) (2016) pp. 132-138.

[21] L. Buhrkall, DC components due to ice on the overhead contact wire of ac electrified railways, Electrische Bahnen 103(8) (2005) pp. 380-389.

[22] S. Midya, D. Bormann, T. Schutte, R. Thottappillil, Pantograph arcing in electrified railways - mechanism and influence of various parameters - Part I: With DC traction power supply, IEEE Trans. on Power Delivery 24(4) (2009) pp. 1931-1939.

[23] MyRailS, Metrology for Smart Energy Management in Electric Railway Systems,

[24] CENELEC EN 50463-2, Railway applications - Energy measurement on board trains, 2017.

[25] R. J. Hill, M. Fracchia, P. Pozzobon, G. Sciutto, A frequency domain model for $3 \mathrm{kV}$ DC traction DC-side resonance identification, IEEE Trans. on Pow. Sys. 10(3) (1995) pp. 13691375.

[26] A. M. Walczyna, P. Janiszzwski, Time domain analysis of harmonic interactions between traction vehicle and DC supply, Intern. Conf. on Electric Railways in a United Europe, 27-30 March, 1995, Amsterdam, Netherlands.

[27] A. Szelag, M. Steczek, Analysis of input impedance frequency characteristic of electric vehicles with a.c. motors supplied by 3 $\mathrm{kV}$ DC system for reducing disturbances in signalling track circuits caused by the harmonics in the vehicle's current, Przeglą Elektrotechniczny 89(3) (2013) pp. 29-33.

[28] V. Šmídl, Š. Janouš, Z. Peroutka, Improved stability of DC catenary fed traction drives using two-stage predictive control, IEEE Trans. on Ind. Electronics 62(5) (2015) pp. 3192-3201.

[29] A. Mariscotti, D. Giordano, Electrical characteristics of pantograph arcs in DC railways: infrastructure influence, Proc. of 
the 23rd IMEKO TC4 Intern. Symp., 17-20 September, 2017, Xi'an, China.

[30] A. Sawicki, Arc models for simulating processes in circuits with a SF6 circuit breaker, Archives of Electrical Engineering 68(1) (2019) pp. 147-159.

[31] J. Paukert, The arc voltage and the resistance of LV fault arcs, Proc. of the 7th Intern. Conf. on Switching Arc Phenomena, 1993, Lodz, Poland, pp. 49-51.

[32] A. Mariscotti, D. Giordano, Filter transients onboard DC rolling stock and exploitation for the estimate of the line impedance, Proc. of Intern. Instrum. and Meas. Tech. Conf., 25-28 May, 2020, Dubrovnik, Croatia.

[33] J. L. Guardado, S. G. Maximov, E. Melgoza, J. L. Naredo, P. Moreno, An improved arc model before current zero based on the bombined Mayr and Cassie arc models, IEEE Trans. on Power Delivery 20(1) (2005) pp. 138-142.

[34] H. Zhou, Z. Liu, Y. Cheng, K. Huang, Extended black-box model of pantograph arcing considering varying pantograph detachment distance, Proc. of IEEE Transp. Electrif. Conf. and Expo (ITEC), 7-10 August, 2017, Harbin, China.

[35] F. M. Uriarte, A. L. Gattozzi, J. D. Herbst, H. B. Estes, T. J. Hotz, A. Kwasinski, R. E. Hebner, A DC arc model for series faults in low voltage microgrids, IEEE Trans. on Smart Grid 3(4) (2012) pp. 2063-2070.

[36] A. Mariscotti, M. Ruscelli, M. Vanti, Modeling of audiofrequency track circuits for validation, tuning and conducted interference prediction, IEEE Trans. on Intel. Transp. Sys. 11(1) (2010) pp. $52-60$.
[37] A. Mariscotti, P. Pozzobon, Synthesis of line impedance expressions for railway traction systems, IEEE Trans. on Vehicular Technology 52(2) (2003) pp. 420-430.

[38] P. Ferrari, A. Mariscotti, P. Pozzobon, Reference curves of the pantograph impedance in DC railway systems, Proc. of IEEE International Conference on Circuits and Systems, 28-31 May, 2000, Geneva, Switzerland, pp. I-555/558.

[39] A. Mariscotti, P. Pozzobon, Experimental results on low rail-torail conductance values, IEEE Trans. on Vehicular Technology 54(3) (2005) pp. 1219-1222.

[40] G. D'Addio, M. Fracchia, A. Mariscotti, P. Pozzobon, Sensitivity analysis of railway line impedance to variations of electrical and geometrical parameters, Proc. of World Congress on Railway Research WCRR, 19-23 October, 1999, Tokyo, Japan.

[41] M. Brenna, F. Foiadelli, Sensitivity analysis of the constructive parameters for the $225-\mathrm{kV}$ high-speed railway lines planning, IEEE Trans. on Power Delivery 25(3) (2010) pp. 1923-1931.

[42] R. Garg, P. Mahajan, P. Kumar, Sensitivity analysis of characteristic parameters of railway electric traction system, Intern. J. of Electronics and Electrical Eng. 2(1) (2014) pp. 8-14.

[43] V. V. Terzija, H. J. Koglin, On the modeling of long arc in still air and arc resistance calculation, IEEE Trans. on Power Delivery 19(3) (2004) pp. 1012-1017.

[44] CENELEC EN 50124-1, Railway applications - Insulation coordination - Part 1: Basic requirements - Clearances and creepage distances for all electrical and electronic equipment, 2017. 